\author{
Military Technical College \\ Kobry El-Kobbah, \\ Cairo, Egypt.
}

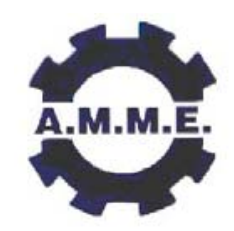

\title{
EFFECT OF STRONTIUM MODIFICATION ON MACHINABILITY OF ALUMINIUM-SILICON EUTECTIC ALLOY
}

\author{
HAQUE$^{*}$ M. M., KHAN ${ }^{* *}$ A. A. and HAJJAJ ${ }^{* * *}$ S. S
}

\begin{abstract}
This work demonstrates and explains the effect of strontium modification on machinability of aluminium-silicon eutectic (LM-6) type alloy. This alloy is known to have many favourable features including great weight to strength ratio, high corrosion resistance and excellent castability. However, LM-6 alloy has poor machinability, which reduces its applications range. In this study, various samples of LM-6 alloy were cast using sand and metallic chill mould with and without strontium addition. Machining on each cast product, was carried out using recommended cutting parameters for Al-Si alloys. Strontium modified samples have recorded a reduction in average flank wear, an increase in shear plane angles and a reduction in chip thickness. The main reason for this improvement is the refining effect of strontium, which reduces the size of the hard silicon particles. As a result, their abrasive action on the tool face has reduced a lot. Dramatic reductions in tool wear rate were also recorded only when the microstructures were refined. On the other hand, when no refinement of microstructure occurs, tool wear rate becomes high. The tool wear depends not only on the phases present in the work material, but also on their sizes and distribution over the entire structure.
\end{abstract}

\section{KEY WORDS}

Eutectic, Wear, Shear, Chip, Abrasive.

\footnotetext{
Professor, Associate Professor and "*** Graduate Student, Department of Manufacturing and Materials Engineering, Kulliyyah of Engineering, International Islamic University Malaysia (IIUM), Gombak, P.O. Box 10, 50728 Kuala Lumpur, Malaysia.
} 


\section{INTRODUCTION}

For the last three decades, the automotive industry saw a steady increase in the demand for improved fuel economy, enhanced safety performance, and reduced exhaust emission. This was coupled with a substantial increase in the use of newer and lighter materials, to achieve weight reduction in high volume passenger vehicles. During the same period, the amount of aluminium and its alloys, used on each vehicle produced worldwide has seen a steady increase [1]. Aluminium applications in the automotive industry cover a wide range of components, from power train components, aluminium wheels, radiators and heat exchanger, chassis, suspension parts, closure panels, pistons and other engine components, as well as primary body structures.

The near-eutectic group of aluminium silicon alloys enjoys common features; low thermal expansion, excellent castability, high corrosion resistance, and high abrasive wear resistance, this has led to their use in automotive piston components. This group of alloys is sometimes referred to as piston alloys, which provide the best overall balance of properties [2]. The eutectic aluminium silicon alloy - or LM-6 alloy - is a member of this group. However, LM-6 alloy has poor machinability, which reduces its applications range [3]. As a result, LM-6 alloy and the rest of the piston alloys are generally cast into shape; however, with more and more automotive technology advances and complicated component shapes, lean manufacturing, and constant changes in design, the need for machining LM-6 alloy has increased.

This brings about the need to investigate possible methods to improve machinability of LM-6 alloy, with the aim of reducing machining time and cost, while improving the quality.

\section{EXPERIMENTAL PROCEDURE}

\section{Moulding Materials}

In order to produce green sand mould (Fig. 1), the moulding mixture was consisted of natural sand having sub-angular grain shape (A.F.S. Fineness No. 110) and 10\% bentonite clay to which about $6 \%$ water was added.

On the other hand, for the production of metallic chill mould (Fig. 2), mild steel was used. This is because; this material in the form of slab was easily and cheaply available in the local market. However, two halves of the mould/die were machined by using Vertical Machining Centre (VMC), which have been designed previously in the MasterCam. The CAD/CAM software helped to create the die geometry to prepare the engineering details and finished blueprints. The milling and grinding operations were conducted by using Vertical Milling Machine and Surface Grinding Machine, respectively.

\section{Preparation of Charge Materials}

The experimental melts were carried out with a basic LM-6 type alloy that is aluminium -silicon eutectic type alloy. Strontium used as a modifying agent, in the form of $\mathrm{Al}-10 \%$ $\mathrm{Sr}$ alloy (supplied by Syarikat Limmet, Malaysia), was added to the charge at the beginning of the melt. This temper alloy was cut into small pieces $(5-8 \mathrm{~mm})$ and kept at 
the bottom of the crucible. As varying degrees of modification exit, it is difficult to decide upon the optimum amount of strontium needed to modify the LM-6 alloy effectively. It depends upon the presence and amount of different impurities in the aluminium-silicon alloy. From the findings of some previous investigators $[4,5], 0.1 \%$ strontium was added to modify the LM-6 alloy in the present study.

\section{Melting, Casting and Superheating}

The charge materials were melted in an induction furnace and superheating temperature of $750^{\circ} \mathrm{C}$ was used and the melts were held at this temperature for about 5 minutes [5]. The melt was then stirred with a rod coated with bentonite slurry and the dross was skimmed off from the top before pouring. The pouring of the melts was carried out at about $700^{\circ} \mathrm{C}$ to $710^{\circ} \mathrm{C}$ into the green sand mould and metallic chill mould in a continuous stream. The tip of the crucible was held just above the pouring cup of the mould and was held in position to avoid any possible turbulence to minimize drossing and hydrogen pick up in the mould.

\section{Machining Test}

For this experiment, ranking machinability tests were conducted. All samples were machined under identical machining settings using recommended cutting parameters for these types of alloys [6,7]. However, it is not always possible to use recommended parameters. Safety constrains, product availability, etc. limited the practitioner's ability to use recommended settings. For instance, every machine has a safety limit; a turning centre may be designed to turn at $2000 \mathrm{rpm}$, but the real limit could be only $1500 \mathrm{rpm}$, due to factors such as vibration, chip control and other hazardous situations. Also, obtaining a tool and a holder combination that match the actual tooling recommendations could be a challenge. Remembering all these, settings were fixed throughout the test and therefore, their effects were also fixed. Thus, machinability settings will not affect the main objective of this work, i.e. to study the effect of modifying LM- 6 alloy, while maintaining fixed machining settings. Table 1 shows cutting speeds ranges for Al-Si alloys along with the corresponding feed rates and depth of cut.

Table 1 Cutting and tooling parameters for Al-Si alloy

\begin{tabular}{|c|c|c|c|}
\hline \multicolumn{2}{|c|}{ Cutting Parameters } & \multicolumn{2}{c|}{ Tooling Parameters } \\
\hline Cutting speed & $500(\mathrm{~m} / \mathrm{min})$ & Tool material & Cemented Carbides, K10 \\
\hline Feed rate & $1(\mathrm{~mm} / \mathrm{rev})$. & Back rake angle & $0^{\circ}$ \\
\hline Depth of cut & $1 \mathrm{~mm}$ & Side rake angle & $15^{\circ}$ \\
\hline & & Side cutting angle & $10^{\circ}$ \\
\hline & & Back cutting angle & $10^{\circ}$ \\
\hline & & Side clearance angle & $5^{\circ}$ \\
\hline
\end{tabular}

\section{RESULTS AND DISCUSSIONS}

When strontium is added to the LM-6 alloy, the microstructure is refined; transforming large silicon needles into fine and well dispersed globular size (Fig. 3). This refining effect becomes more prominent when metallic chill mould is used for casting. The 
rapidly cooled casting in chill mould possesses finer structure compared to the slowly cooled casting in sand mould. Consequently, the properties of chill cast product have higher values and better performance.

However, strontium modified samples recorded a little reduction in hardness with an increase in ductility for both rates of cooling [8]. The reason may be that the modified alloy contains no flat type or diamond shaped primary or needle shaped hard and brittle silicon phase, resulting lower hardness. Another reason might be that the modified alloy showed more porosity than the un-modified LM-6 alloy [9], showing lower hardness.

Figures 4 and 5 show the machining time, chip analysis and tool wear during machining for sand cast and metallic chill cast LM-6 alloy, respectively under un-modified and strontium modified condition. Due to refinement of silicon phases in the structures in modified alloy, the tool wear rate is reduced. As it can be seen from the figures, the tool that cut the modified sample showed reduced abrasive wear in comparison with the unmodified sample. Thus, it can be concluded that the strontium modifying effect resulted in refining the hard silicon phases, which reduces its abrasive effect, and thus, in turn the tool wear rate is reduced. The reduction of cutting forces is attributed directly to the reduction of hardness. Gore et. al. [10] reported that reduced hardness requires reduced cutting forces and ultimately reduced tool wear.

The figures also show the chips extracted from the same samples and the analysis is focused on chip thickness and shear plane angle. Chip analysis serve as a good demonstration of machining cutting forces. Thick chips associated with small shear plane angle represent high cutting forces, while thin chips with large shear plane angles represent low cutting forces $[6,11]$. Comparing the two samples in the figures, it can be seen that strontium-modified sample produced a thinner chip thickness with a larger shear plane angle. This demonstrates that cutting forces in the strontium-modified samples are less than those in the unmodified sample.

Machinability of an alloy depends on two major factors; the first one is the status of the work material, which is its microstructure, physical and mechanical properties, etc. This factor has a direct impact on machinability. The second one is the machining environment, i.e. the cutting parameters, tooling settings and other miscellaneous settings. This factor has an indirect effect on machinability.

As it is known that very high ductility is the cause of poor machinability of the material, and as strontium addition resulted in increasing the ductility of Al-Si alloy, therefore, it could be expected that this increase in ductility would worsen machinability. In essence, strontium addition resulted in three different changes in the LM-6 type alloy, such as refining the microstructure, reducing the hardness and increasing the ductility. The first two changes improve the machinability, while the last one should worsen machinability. However, as the figures show, the strontium addition resulted in improving machinability. This leads to the conclusion that the effect of strontium on increasing ductility was overwhelmed by its effect on microstructural refinement and improvement of physical properties [8], and that the net change was improving machinability.

\section{CONCLUSIONS}

The following conclusions can be drawn from the results of the present investigation: 
(i) Strontium addition to LM-6 alloy has resulted in refining the microstructure; changing the morphology of silicon particles from large needles to fine and nodular shapes., well dispersed in the aluminium matrix. At the same time, strontium addition to LM- 6 resulted in a reduction in hardness and an increase in ductility.

(ii) Due to these changes, machinability of the LM-6 alloy has been improved, which has resulted in reducing abrasive wear of the tool and the cutting force. The tool wear depends not only on the phases present in the work material, but also on their sizes and distribution over the entire structure. Strontium has well dispersed the silicon particles over the aluminium matrix and as a result, a reduction of $36 \%$ tool wear rate has been observed in the present study.

(iii) The combined effect of cooling rate and modification has refined the grains and reduced the size of different phases in the microstructure of the metallic chill or die cast alloy during solidification. Thus, strontium modification has better effect on machinability of die cast alloy compared to that of the sand cast LM-6 alloy.

\section{ACKNOWLEDGEMENT}

The authors are grateful to the Ministry of Science, Technology and Innovation (MOSTI) for sanctioning the necessary funds to carry out the present investigation. The authors are indebted to the Dean, Kulliyyah of Engineering for providing them the necessary facilities in the Kulliyyah without which, the various works of the project would not be performed smoothly.

\section{REFERENCES}

[1] Sherman, A.M., "Trends in automation applications for aluminium", Proceedings of The $7^{\text {th }}$ International Conference of the Aluminum Association (ICAA7), Charlottesville, Virginia: Science Forum. Vols. 331-337, p. 3, (April 2000).

[2] Day, R. D., Smart, R. F. and Tommis, N., Associated Engineering (A. E.) Technical Symposium, Paper No. 4, U. K., (1970).

[3] Warmuzek, M., "Aluminum-Silicon Casting Alloys", Atlas of Microfractographs, ASM International, Materials Park, USA, p. 14, (2004).

[4] Seleznev, L. P., Borovitskaya, G. P. and Kuznetsova, E. V., J. Institution of Science and Research Project on Light Metals and Alloys, Vol. 58, p. 63, (1978).

[5] Haque, M. M., "Strontium Modification of Aluminium-Silicon Eutectic Alloy and Factors Affecting it", Metals Forum, Vol. 6, No. 1, p. 54, (1983).

[6] Boothroyd, G and A-Knight, W, Fundamentals of Machining and Machine tools, $2^{\text {nd }}$ Edition, New York: Mercel Dekker Inc., p 133, (1989).

[7] Walsh, R., Machining and Metalworking Handbook, $2^{\text {nd }}$ Edition, McGraw Hill, p. 587, (1999).

[8] Sami Salama Hajjaj, M. Sc. Thesis, Kulliyyah of Engineering, Int. Islamic University Malaysia (IIUM), (2007)

[9] Haque, M. M., "Effect of Strontium on Structure and Properties of Aluminium Silicon Alloys", J. of Materials Processing Technology, Printed by Elsevier Science S.A., Vol. 55, p.193, (1995). 
[10] Gore, G.J. and Gates, J.D. "Effect of hardness on three very different forms of wear", Wear. p. 203, (1997).

[11] Trent, E. M., Metal Cutting, $3^{\text {rd }}$ Edition, Butterworth, Oxford, p. 254, (1991).

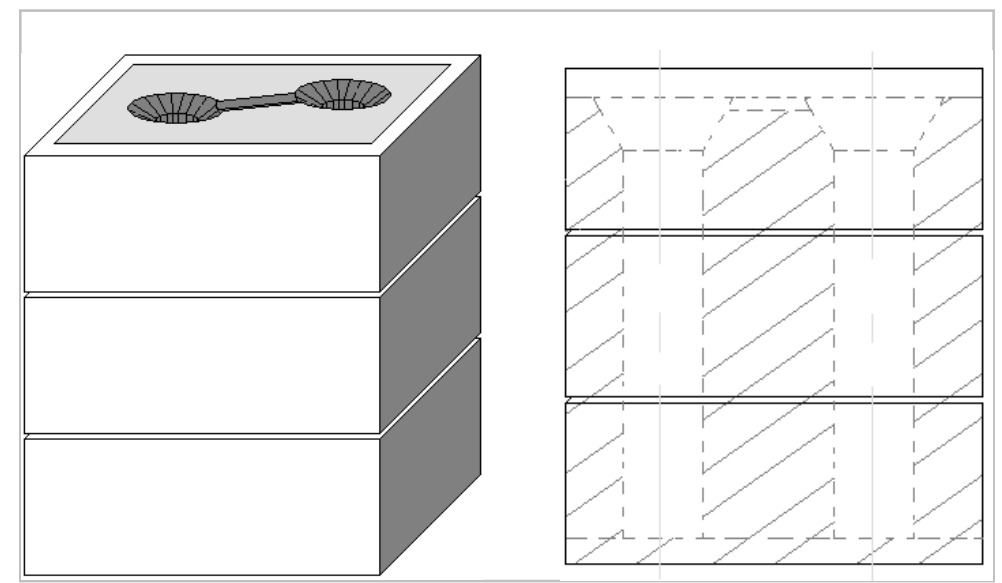

Fig. 1. Showing green sand mould.

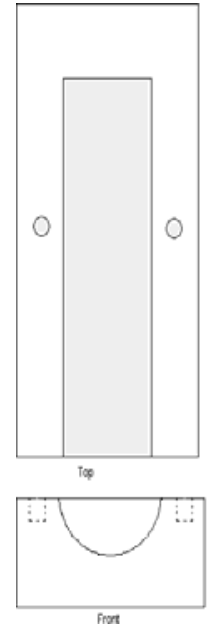

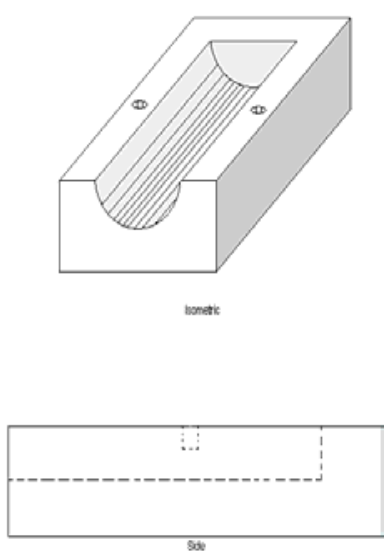

(a)

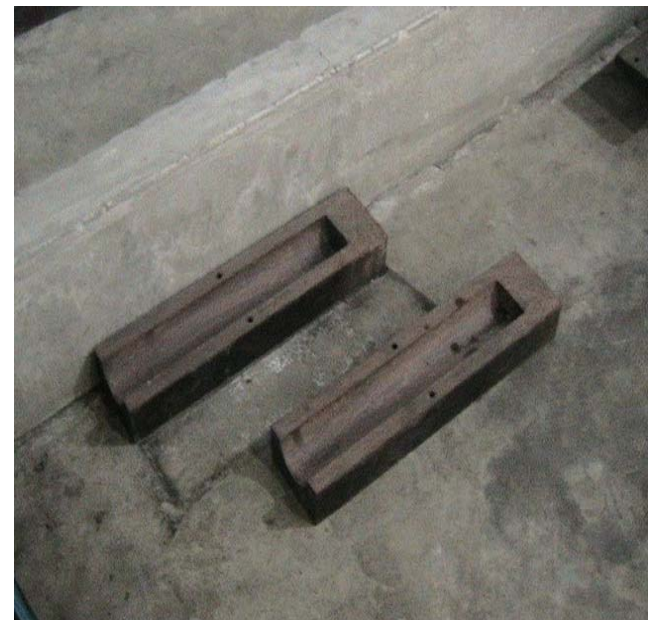

(b)

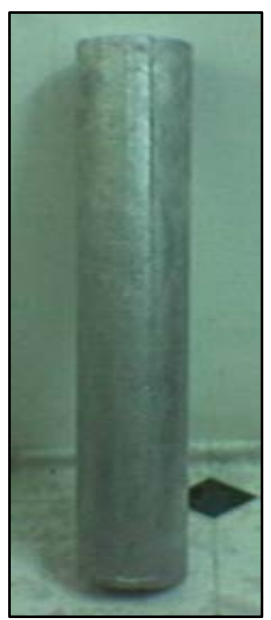

(c)

Fig. 2. Showing (a) Details of die groove, (b) Die halves and (b) Chill cast LM-6 alloy. 


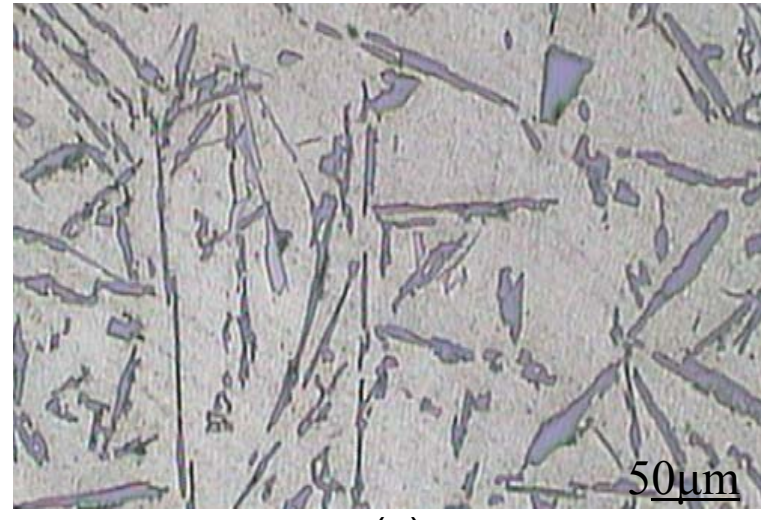

(a)

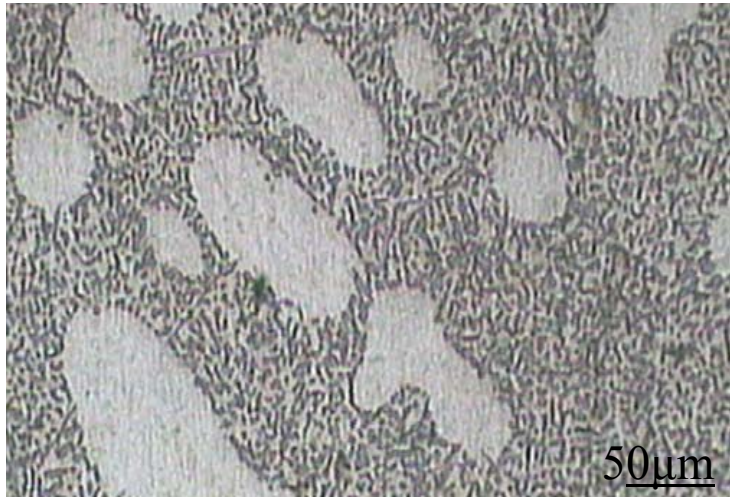

(b)

Fig. 3. Microstructures of sand cast LM-6 alloy, (a) unmodified and (b) Sr-modified.
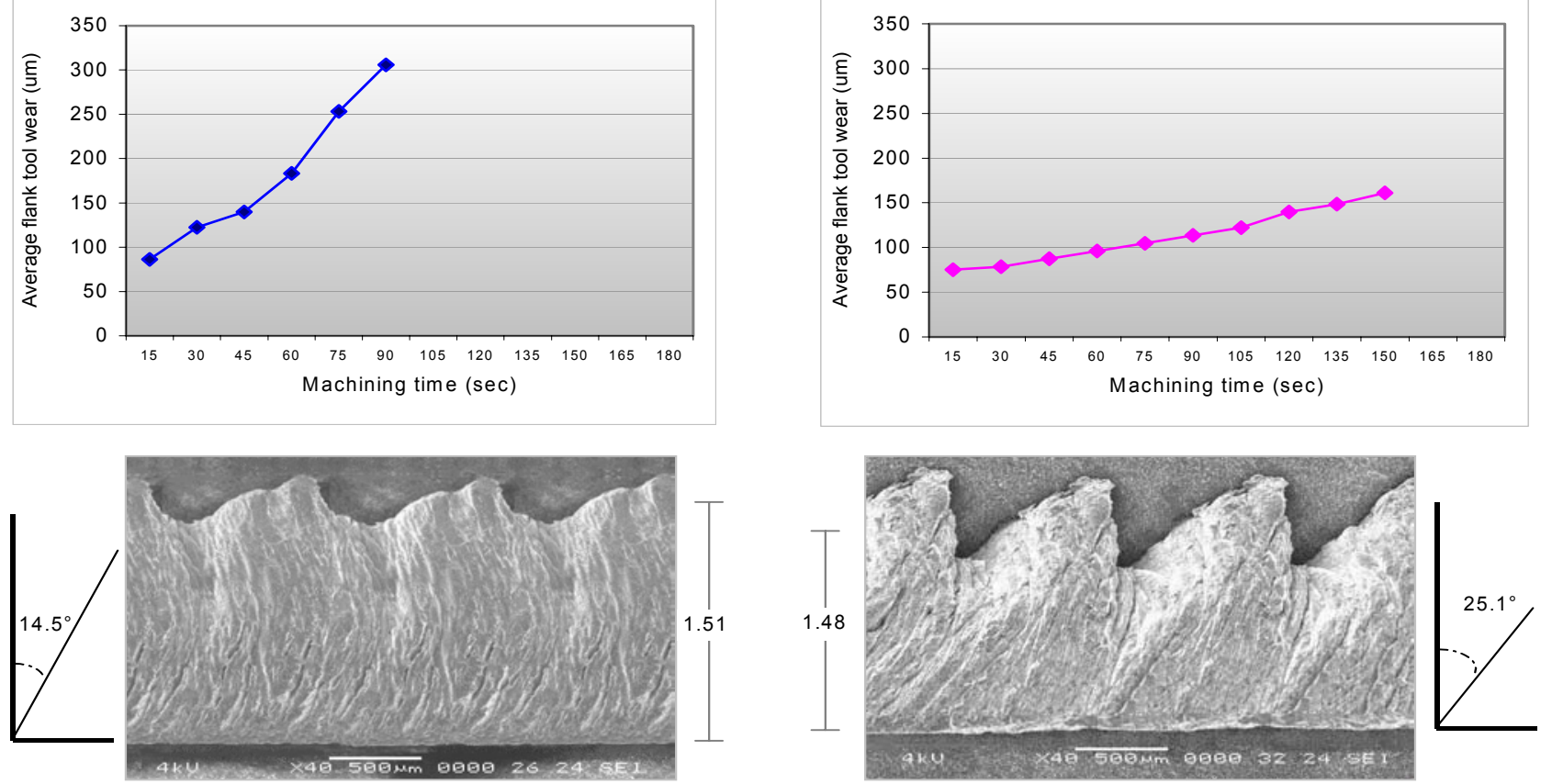

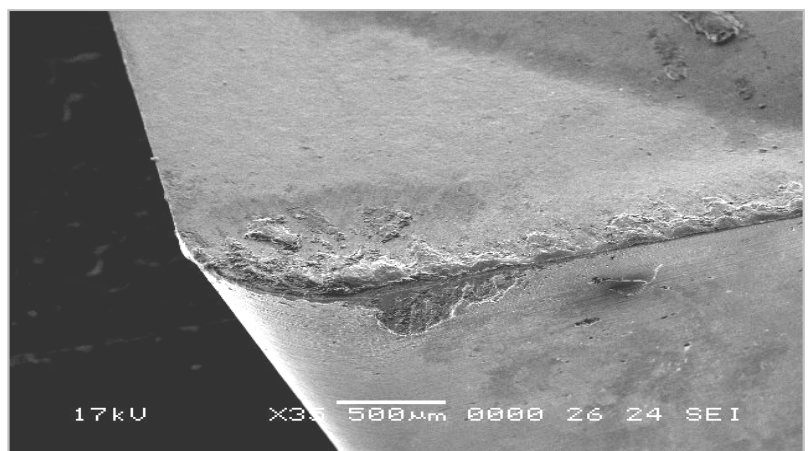

Sand cast LM6

(a)

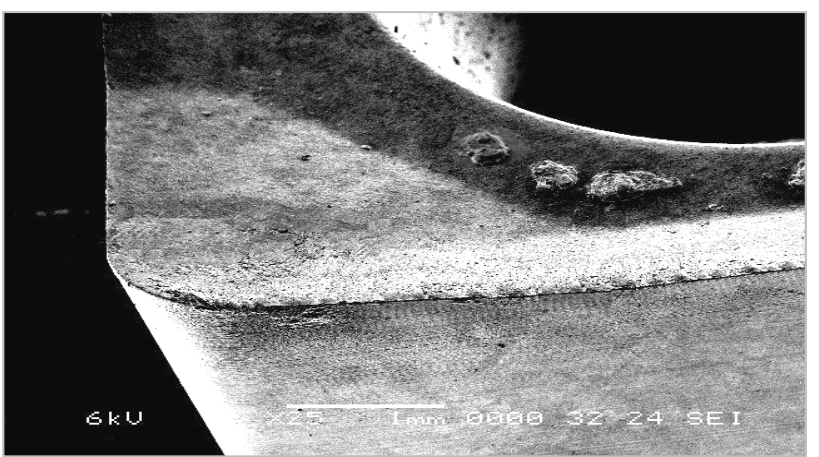

Sr- Sand cast LM6

(b)

Fig. 4. Showing machining time, chip analysis and tool wear during machining for sand cast LM-6 alloy, (a) Un-modified and (b) Sr-modified. 

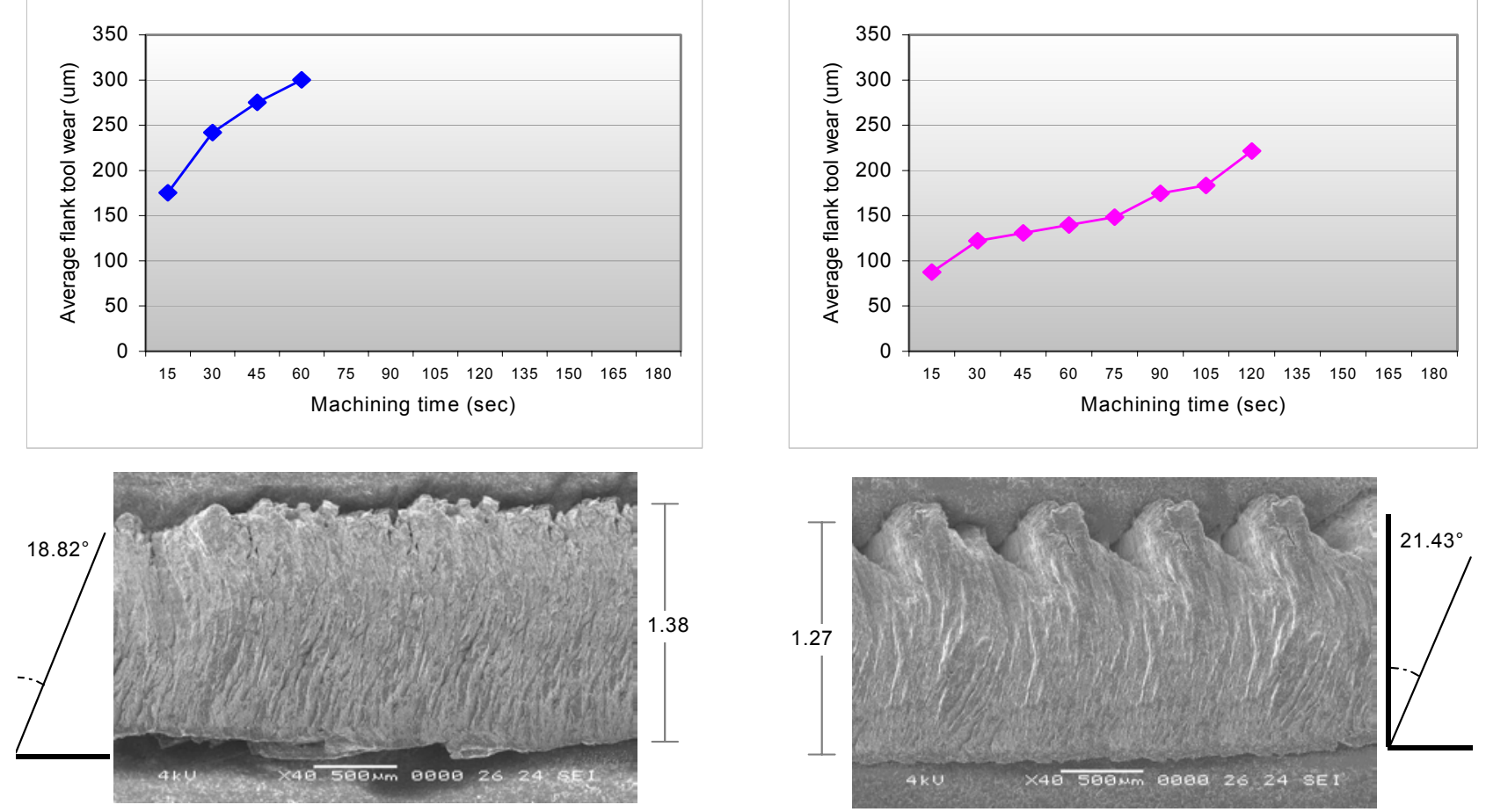

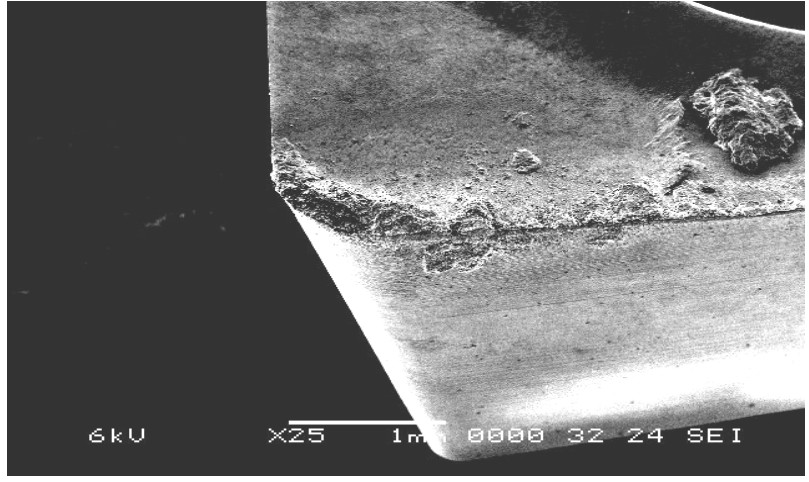

Die cast LM6

(a)

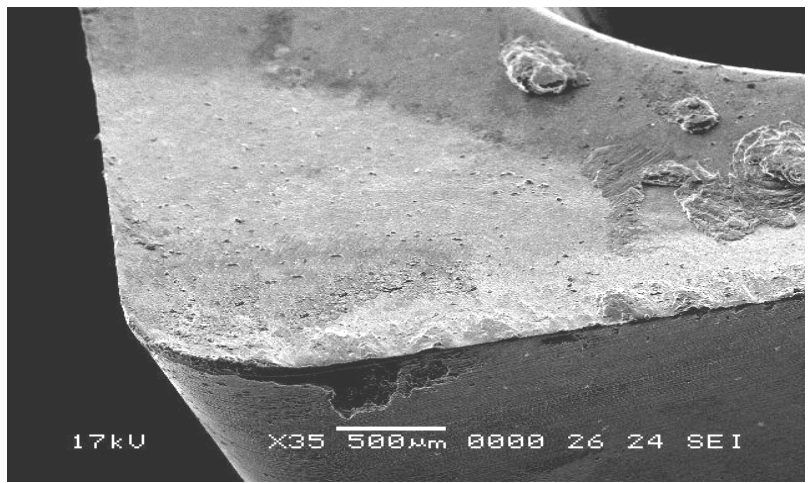

Sr- Die cast LM6

(b)

Fig. 5. Showing machining time, chip analysis and tool wear during machining for metallic chill cast LM-6 alloy, (a) Un-modified and (b) Sr-modified. 